\title{
Legal approach regarding dental malpractice in Romania
}

\author{
Adela CRISTINA LAZĂR ${ }^{1)}$, DAN BUHĂTEL ${ }^{1)}$, OVIDIU MUREŞAN ${ }^{2)}$, LIANA TODOR ${ }^{3)}$, MARIANA PĂCURAR ${ }^{4)}$ \\ 1) Department of Oral Rehabilitation, Iuliu Hatieganu University of Medicine and Pharmacy, Cluj-Napoca, Romania \\ 2) Department of Oral and Maxillofacial Surgery, Iuliu Hatieganu University of Medicine and Pharmacy, Cluj-Napoca, Romania \\ ${ }^{3)}$ Department of Dental Medicine, Faculty of Medicine and Pharmacy, University of Oradea, Romania \\ 4) Department of Orthodontics, George Emil Palade University of Medicine, Pharmacy, Science, and Technology of Târgu Mures, \\ Romania
}

\begin{abstract}
In Romania, the term dental malpractice is relatively new compared to medical malpractice. The common premises that underlie these iatrogenics have made doctors more vigilant about treatment and achieving the desired results. At the same time, the conditions of medical liability are consistent with those of civil liability, namely: damage, wrongdoing, guilt, and causation. To counteract these effects, public attention has been focused in recent years on patients' rights (involving, causes, effects, informed consent of the patient regarding the collection of personal data, informing the patient about the work itself, and possible complications which may occur postoperatively). As a result, the number of reported cases of malpractice has increased markedly in recent years.
\end{abstract}

Keywords: dental malpractice, law, consent, first aid.

\section{ㅁ Introduction}

The process of medical malpractice is a medical act committed by a specialist/primary care physician who deviates from the standards and regulations established as treatment protocols and which results in the medical injury of a patient. Therefore, there are situations of iatrogenics that can occur in any medical field [1-4].

Another term associated with medical malpractice is considered 'medical negligence', i.e., a negligent act of a specialist/primary care physician who ignores and thus jeopardizes the protocols and standards required at national level [5].

Dental malpractice is very similar to medical malpractice legally and administratively. Thus, a general dentist or specialist/mayor knowingly commits a dental iatrogenicity, it ends up causing the patient dental damage in the short or long term, with repercussions on the general health [1].

Globally, the problem of medical and dental malpractice has increased in recent years. However, it is quite difficult to collect data from each state, as new cases are constantly being updated, which makes this phenomenon global and constantly updated. To counteract these effects, public attention has been focused in recent years on patients' rights (involving effects, causes, informed consent of the patient regarding the collection of personal data, informing the patient about the work itself, and possible complications, which may occur postoperatively). As a result, the number of reported cases of malpractice has increased markedly in recent years in many parts of the world [6].

Like any other healthcare professional, dentists are also exposed to the risks of causing patients' iatrogenicity, which can lead to defendants of malpractice. In such cases, if a dentist performs some procedures that can put at risk the life of his patient deliberately or accidentally, he should face legal consequences $[7,8]$. Procedures performed by general practitioners or specialists/primary care professionals are complex and require a high level of knowledge and practice [9].

In Romania, the cases underlying the claims against dentists are based on negligence, non-compliance with the principle of confidentiality, lack of patient consent, intentional mistakes, breach of contract, such as guaranteeing a certain aesthetic unfavorable result for the patient [10]. At the same time, the premises of medical liability are consistent with those of civil liability, namely: wrongdoing, guilt, damage, and causation [11].

\section{ㅁ Dental malpractice}

"Nemo censetur ignorare legem" is a Latin expression that refers to the principle, applicable in criminal law, according to which ignorance or misunderstanding of the law does not remove the obligation of persons to comply with the law and to answer for its violation. The same principle applies in the criminal process, each citizen being obliged to know the law. No one can allege ignorance of the rule of criminal proceedings or error in those regulations.

Dental malpractice is considered a definite problem that more and more dentists are facing. The general context of dental malpractice is perceived differently by patients, dentists, or lawyers, depending on the professional training of each and the given circumstances. All dentists are accustomed to different types of patients. Thus, in addition to professional dental training, the dentist must have a well-cultivated ability to communicate with patients, so that in the short or long term to create a professional

This is an open-access article distributed under the terms of a Creative Commons Attribution-NonCommercial-ShareAlike 4.0 International Public License, which permits unrestricted use, adaptation, distribution and reproduction in any medium, non-commercially, provided the new creations are licensed under identical terms as the original work and the original work is properly cited. 
doctor-patient relationship based on respect, trust, and seriousness.

But there are situations in which this relationship can be disrupted due to failures on the part of the dentist or even the patient. These failures may be deliberate on the part of the dentist, who in these cases ignores established dental protocols, or may be unintentional, caused by various aspects of a human nature (inadequate condition/disposition of the dentist to perform a maneuver) or material (the materials used have expired, the utensils used are inadequate in terms of quality, in this case creating medical damage to the patient concerned.

There are many types of complaints, some of which can be resolved medically, others not. Most dentists tend to believe that any complaint made by patients can lead to allegations of malpractice. Therefore, each individual dentist should acquire some basic information about the concept of dental malpractice, its fundamental principles, and possible models of liability for the provision of correct dental treatment $[12,13]$.

So far, neither in Romania, nor in the other countries in the EU, there are no specific laws for each medical profession. This has repercussions on how to deal with allegations of dental malpractice. On the other hand, most dentists are not aware of the importance of the laws already in force, which can protect them in extreme situations. Unfortunately, few doctors know these organic medical laws.

According to the international scientific literature, so far, there are a lot of reviews, monographs, original articles that address the topic of dental malpractice and its related aspects. The abundance of information also results from statistics performed at national level, but especially internationally in terms of biomedical (etiology, practice guides), financial and social aspects. Globally, an overwhelming number of studies point out that the number of cases of dental malpractice is on the rise [1215]. But the concept of dental malpractice is not a relatively new one. According to the medical scientific literature, the first reported case of malpractice was in Britain in the XIVth century between Agnes of Stratton and John Swanlond [16]. Since then, cases of dental malpractice have steadily increased. This aspect generates repercussions on the professional image of the doctor, but also financial consequences. Currently, the costs of dental insurance, damages and compensation are increasing [16]. Regarding civil medical liability, there are several universal conditions that must be met (Figure 1) so that a dentist is eligible for the charge of malpractice [17]. These conditions are valid in both national and international law systems.

\section{a General Data Protection Regulation (GDPR)}

GDPR is the strictest security law in the world. It was edited and adopted by the European Union (EU) and requires organizations and implementation in its original form around the world to protect the personal data of EU citizens. The regulation was valid starting on May 25,2018 . If it is not respected all the forms of the initial regulation, there will be harsh fines against those who violate privacy and security standards, with total penalties of millions of euros.

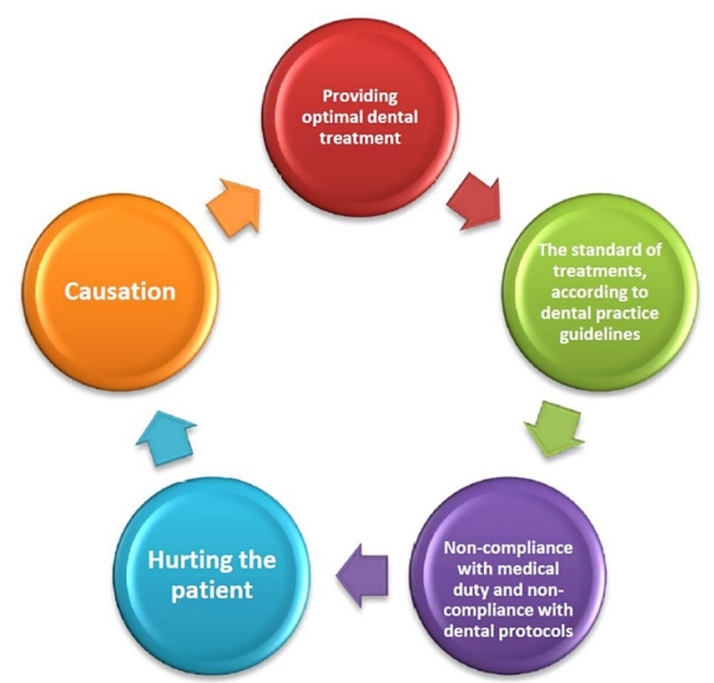

Figure 1 - Eligible conditions for dental malpractice.

The right to privacy is part of the 1950 European Convention on Human Rights, which states: "Everyone has the right to respect for his private and family life, his home and his correspondence." Thus, through legislation, the EU tried to ensure the protection of citizens' data.

Due to the evolution of technology and the Internet, in 1995, the EU adopted the European Data Protection Directive, setting minimum standards for the confidentiality and security of data, based on which each Member State based its own implementing law. Consequently, in 1994, the first banner of an add appeared online. Since the year of 2000, most global financial corporations have offered to their customers the service of online banking. In the year of 2006, the Facebook social networking platform opened to the public. It was the beginning of a new era, a digital era with countless opportunities. In next years, the citizens became more aware of the benefits but also of the risks that may arise with online shopping. In the year of 2011, a Google user sued the company for scanning his e-mails. Two months later, the European Data Protection Supervisor said the EU needs a "comprehensive approach to the protection of personal data" of the clients and has begun work on updating the 1995 directive regarding this matter.

On 25 May 2018, the GDPR became valid and after passing through the European Parliament all organizations from every country from the EU were required to comply [18].

With the launch of the GDPR, Europe strengthens its strong position on data privacy and security in a period of time when technology is evolving, and by entrusting personal or financial data through cloud services, thus facilitating the copying of such data by others. Personal data that are required when filling an online document that relates to a person who can be identified by name, surname, telephone number and e-mail addresses are obviously personal data. Moreover, certain information about location, ethnicity, gender, biometric data, religious beliefs, web cookies and political opinions may also be considered personal data. Therefore, the users need to be cautious when fill online all the personal data that are required.

In the situation where the patients' data are processed within a dental office/clinic, this aspect must be done 
according to Art. 5.1-2 of the GDPR EU, respecting the six principles of protection of personal data of patients: legality and transparency - that patient needs to be informed that his personal data are collected only for professional purpose; purpose limitation - personal data should be collected for legitimate purposes explicitly specified to the patient; data minimization - collecting absolutely necessary data; accuracy - keeping personal data accurate and up to date; storage limitation - strict storage of personal data only for the purpose of a specific medical purpose; integrity and confidentiality - use the encryption of patient data when processing data to ensure adequate security, integrity, and confidentiality.

According to Art. 6 of the GDPR EU and Chapter III of Law No. 677/2001, there are special situations in which patients' personal data may be disclosed to third parties: the data subject gave his/her specific consent, without ambiguity, to process the data (e.g., he/she subscribed to the marketing e-mail list of the dental office/clinic); data processing is necessary for concluding a collaboration/ rental contract of which the data subject is a part; data processing in order to save the life of a patient in critical situations; processing is necessary to perform a task in the public interest or to perform certain official functions. There is also a legitimate interest in processing a patient's personal data. This is the most flexible legal basis, although the 'fundamental rights and freedoms of the data subject' always outweigh your interests, especially when it comes to the data of a person under 18 years old [19-21].

In Romania, there is the National Data Protection Authority (The National Supervisory Authority for the Processing of Personal Data - ANSPDCP), which has the power to prohibit the processing of data from special categories, even if the data subject has given his consent - including if he has given his written and unequivocal consent, or if does not fall into one of the exceptions explained above. Authorization must be requested and obtained in advance from the supervisory authority. Any processing of personal data outside the limits provided for in the authorization is prohibited. If it is not an emergency, the authorization can be granted only after consulting the Romanian College of Dentists [22].

\section{ค Patients written consent}

It represents an indispensable act in any dental office/ clinic. In EU, there are strict rules regarding a patient's consent to obtain and process personal data. Therefore, in Table 1 we set out the mandatory characteristics of any informed consent handed to the patient before any dental procedure.

Table 1 -Characteristics of the informed consent of the patient in the dental office

- Written agreement must be "specific, informed and unambiguous";

- The agreement at the beginning of the dental treatment must be formulated clearly, precise and to be distinguished from the other aspects related to the dental treatment itself;

- Patients may withdraw their initial consent whenever they wish, and the decision must be honored;

- Children under the age of 18 cannot complete and sign the consent; only the parent or a legal guardian can sign this official act;

- Archiving the consents of all patients.
In Romania, it appeared the Order No. 1411/2016 regarding the modification and addition of the Order of the Ministry of Public Health No. 482/2007 regarding the approval of the Methodological Norms for the application of Title XV "Civil liability of medical staff and the provider of medical, sanitary and pharmaceutical products and services" of Law No. 95/2006 on health care reform. This law order presents a model for the patient's informed consent form, which must be used by all dentist in Romania. Its absence represents a disciplinary violation and will be sanctioned by the disciplinary commission. The lack of the patients consent also leads to inoperable malpractice insurance [23].

\section{ㅁ Romanian Deontological Code of Dentists}

According to the Decision No. 15/2010 on the adoption of the Deontological Code of the Dentist, published in the Official Gazette, Part I, No. 408 of 18.06.2010 and the rectification published in the Official Gazette, Part I, No. 757 of 12.11.2010, stipulates a general Deontological Code for Dentists, regardless of specialization, valid only in Romania. This code contains the mandatory norms of moral and professional conduct, in connection with the exercise of the doctor's rights and duties as a professional, towards patients and other dentists. The purpose of this Code of Ethics is to: promote a relationship of trust and confidence between the dentist and the patient; promote a professional behavior between the members of the medical team; defines and stipulates the misconducts from the professional discipline; defends the reputation of dentists; guarantees professional secrecy.

The details mentioned in this code of ethics are valid for dentists regardless of specialization, nationality, members of the European Community, doctors who are members of the Romanian College of Dentists, members of the Swiss Confederation who practice dentistry in Romania. Therefore, in addition to the material and personal benefits and satisfactions obtained from the exercise of the profession, the dentist has certain obligations, stipulated by law, without which he does not benefit from the protection of Romanian College of Dentists in case of any malpractice accusation.

According to Romanian Deontological Code of Dentists, Art. 20, before any dental operation, the dentist has the obligation to prepare primary evidence documents, regarding the established diagnosis and the treatment plan performed per day. These documents are kept in the archives of the dental office/clinic for five years. However, in cases where the patient or a legal representative needs a copy of the patient's file, the dentist may issue that copy. This approach is considered legal, according to the legal provisions in force.

Relationships between dentists are vital for the correct diagnosis and treatment plan applied to the patient. The interdisciplinary collaboration is meant to strengthen the professional and collegial relations between the dentists, the beneficiary of this collaboration being the patient himself. However, there are situations of conflict, which are not ethical and moral in the profession of dentist [24, 25]. According to the Romanian Deontological Code of 
Dentists, Chapter III, Art. 22-28, there are rules of professional conduct in the dental office/clinic (Table 2).

Table 2 - Rules of professional conduct according to the deontological code of the dentist - The dentist must treat his patients as he himself would like to
be treated by others;

- Defending a colleague unjustly accused;

- It constitutes a disciplinary violation to blame and defame colleagues in front of the patient, the medical staff, as well as any expression or act capable of shaking the patient's trust in the attending physician and his authority;

- In case of disagreements that cannot be settled peacefully, address to the management of the college of which they are part for their resolution, in accordance with the legal provisions in force;

- Dentists who consult a patient together have the duty to avoid during or as a result of a consultation, to discuss in contradiction or to denigrate each other in front of the patient or his family;

- The dentist does not have the right to rule on the treatments of another colleague, unless the patient's health is endangered;

- When several dentists collaborate in the examination or treatment of a patient, they must inform each other;

- The dentist must encourage and support his younger colleagues.

\section{a Conclusions}

The general context of dental malpractice is perceived differently by patients, dentists, or lawyers, depending on the professional training of each and the given circumstances. All dentists are accustomed to different types of patients. Thus, in addition to professional dental training, the dentist must have a well-cultivated ability to communicate with patients, so that in the short or long term to create a professional doctor-patient relationship based on respect, trust, and seriousness. In conclusion, dental malpractice is a situation that can be prevented, if there is a good doctor-patient collaboration from the beginning of treatment, if it is explained to the patient's understanding all the operations to be performed and of course the patient to understand and accept all the necessary steps in the quality treatment he hopes to obtain. However, if the situation evolves in such a way as to lead to accusations of malpractice, the dentist benefits from the defense from county's or national College of Dentists. For the prestige of each dentist, even if it is at the beginning of his career or at the end of his career, this process of malpractice can be avoided through good collaboration and professional relationship with our patients.

\section{Conflict of interests}

The authors declare that they have no conflict of interests.

\section{References}

[1] Manca R, Bruti V, Napoletano S, Marinelli E. A 15 years survey for dental malpractice claims in Rome, Italy. J Forensic Leg Med, 2018, 58(8):74-77. https://doi.org/10.1016/j.jflm. 2018.05.005 PMID: 29772451

[2] Kasahara N, Matsunaga S, Yamada M, Nakamura Y, Tashiro M, Hashimoto M. Comparison of characteristics of dental malpractice trials between medical malpractice and ordinary divisions in district courts. Bull Tokyo Dent Coll, 2020, 61(2): 73-82. https://doi.org/10.2209/tdcpublication.2019-0015 PMID: 32522934
[3] Blau I, Levin L. Medical malpractice: an introduction for the dental practitioner. Quintessence Int, 2017, 48(10):835-840. https://doi.org/10.3290/j.qi.a39106 PMID: 29034379

[4] Berlin L. Medical errors, malpractice, and defensive medicine: an ill-fated triad. Diagnosis (Berl), 2017, 4(3):133-139. https:// doi.org/10.1515/dx-2017-0007 PMID: 29536927

[5] Bal BS. An introduction to medical malpractice in the United States. Clin Orthop Relat Res, 2009, 467(2):339-347. https:// doi.org/10.1007/s11999-008-0636-2 PMID: 19034593 PMCID: PMC2628513

[6] Conrad DA, Whitney C, Milgrom P, O'Hara D, Ammons R, Fiset L, Vesneski W. Malpractice premiums in 1992: results of a national survey of dentists. J Am Dent Assoc, 1995, 126(7): 1045-1056. https://doi.org/10.14219/jada.archive.1995.0283 PMID: 7629349

[7] Ventä I, Lindqvist C, Ylipaavalniemi P. Malpractice claims for permanent nerve injuries related to third molar removals. Acta Odontol Scand, 1998, 56(4):193-196. https://doi.org/10. 1080/00016359850142772 PMID: 9765008

[8] Ozdemir MH, Saracoglu A, Ozdemir AU, Ergonen AT. Dental malpractice cases in Turkey during 1991-2000. J Clin Forensic Med, 2005, 12(3):137-142. https://doi.org/10.1016/j.jcfm.2005. 01.003 PMID: 15914308

[9] Coculescu BI, Coculescu EC, Purcărea VL. Orientation to the patient as a marketing strategy in the Romanian healthcare system. J Med Life, 2016, 9(3):302-305. PMID: 27974940 PMCID: PMC5154320

[10] Vladescu C, Scintee SG, Olsavszky V, Hernandez-Quevedo C, Sagan A. Romania: health system review. Health Syst Transit, 2016, 18(4):1-170. PMID: 27603897

[11] Purcărea VL, Coculescu BI, Coculescu EC. The concept of marketing in the public-private partnership in the medical system in Romania. J Med Life, 2014, 7(Spec Iss 3):20-22. PMID: 25870689 PMCID: PMC4391419

[12] Lakey CK, Nicholas PK, Wolf KA, Leuner JD. Health care and nursing in Romania. J Adv Nurs, 1996, 23(5):1045-1049. https:// doi.org/10.1046/j.1365-2648.1996.10826.x PMID: 8732535

[13] Corte-Real A, Caetano C, Dias Pereira A, Rocha S, Alves S, Nuno-Vieira D. Risk and limits in dental practice: a Portuguese approach to medical-legal evaluation and professional liability. J Forensic Odontostomatol, 2020, 1(38):2-7. PMID: 32420907

[14] Corte-Real A, Caetano C, Alves S, Dias Pereira A, Rocha S, Nuno Vieira D. Patient safety in dental practice: lessons to learn about the risks and limits of professional liability. Int Dent J, 2021, Feb 24, S0020-6539(20)36545-X. https://doi.org/ 10.1016/j.identj.2020.12.014 PMID: 33640155

[15] Mellor AC, Milgrom P. Prevalence of complaints by patients against general dental practitioners in greater Manchester. Br Dent J, 1995, 178(7):249-253. https://doi.org/10.1038/sj.bdj. 4808726 PMID: 7734224

[16] René N, Owall B. Malpractice reports in prosthodontics in Sweden. Swed Dent J, 1991, 15(5):205-217. PMID: 1767367

[17] Oyebode F. Clinical errors and medical negligence. Med Princ Pract, 2013, 22(4):323-333. https://doi.org/10.1159/000346 296 PMID: 23343656 PMCID: PMC5586760

[18] Bookman K, Zane RD. Surviving a medical malpractice lawsuit. Emerg Med Clin North Am, 2020, 38(2):539-548. https://doi.org/ 10.1016/j.emc.2020.01.006 PMID: 32336339

[19] Staunton C, Slokenberga S, Mascalzoni D. The GDPR and the research exemption: considerations on the necessary safeguards for research biobanks. Eur J Hum Genet, 2019, 27(8):1159-1167. https://doi.org/10.1038/s41431-019-0386-5 PMID: 30996335 PMCID: PMC6777499

[20] Orel A, Bernik I. GDPR and health personal data; tricks and traps of compliance. Stud Health Technol Inform, 2018, 255: 155-159. PMID: 30306927

[21] Donnelly M, McDonagh M. Health research, consent and the GDPR exemption. Eur J Health Law, 2019, 26(2):97-119. https://doi.org/10.1163/15718093-12262427 PMID: 31059476

[22] Yuan B, Li J. The policy effect of the general data protection regulation (GDPR) on the digital public health sector in the European Union: an empirical investigation. Int J Environ Res Public Health, 2019, 16(6):1070. https://doi.org/10.3390/ijerph 16061070 PMID: 30934648 PMCID: PMC6466053

[23] Timofte C, Cretu S. Romania - national GDPR implementation overview. OneTrust DataGuidance, Regulatory Research 
Software, 2021. https://www.dataguidance.com/notes/romanianational-gdpr-implementation-overview

[24] Macpherson Mayol I, Roqué Sánchez MV, Gonzalvo-Cirac M, de Ribot E. Estudio comparativo de tres modelos occidentales de códigos deontológicos para odontólogos [Comparative study of three Western models of deontological codes for dentists]. Cuad Bioet, 2013, 24(82):367-376. PMID: 24483313

[25] Graskemper JP. Ethical advertising in dentistry. J Am Coll Dent, 2009, 76(1):44-49. PMID: 19537484

\section{Corresponding authors}

Dan Buhăţel, Lecturer, DMD, PhD, Department of Oral Rehabilitation, luliu Haţieganu University of Medicine and Pharmacy, 15 Victor Babeş Street, 400012 Cluj-Napoca, Cluj County, Romania; Phone +40745-390 915, e-mail: dbuhatel@yahoo.com

Liana Todor, Associate Professor, DMD, PhD, Department of Dental Medicine, Faculty of Medicine and Pharmacy, University of Oradea, 101 December Square, 410068 Oradea, Bihor County, Romania; Phone +40723-517 100, e-mail: liana.todor@gmail.com

Received: February 4, 2021

Accepted: September 16, 2021 